\title{
Influence of atmosphere turbulence and laser coherence on the identification method based on interference multiple-beam scanning of optical targets
}

\author{
${ }^{1}$ Zhao Yan-zhong, ${ }^{2} \mathrm{He}$ Ting,,${ }^{1}$ Shan Cong-miao and ${ }^{1}$ Sun Hua-yan \\ ${ }^{1}$ Department of Electronic and Optical Engineering, Space Engineering University, \\ Beijing, China \\ ${ }^{2}$ North China Research Institute of Electro-optics, Beijing, China
}

Received: 04.09.2017

\begin{abstract}
Using an extended Huygens-Fresnel diffraction integral, we have derived analytical formulae that describe a partially coherent array of Gaussian beams passing through an optical target and going back along the entrance way in a turbulent atmosphere. These formulae include the light intensity distribution at the return place, as well as the light intensity distribution and the spatial correlation at the target place. Using numerical calculations, we have studied the effects of laser coherence length and turbulence strength on the interference fringe contrast and the spatial coherence degree at the target place, together with the light intensity distribution at the return place and the system operating range. We have found that the fringe contrast and the spatial coherence degree at the target place decrease with increasing turbulence strength and decreasing laser coherence length. Then the contrast of light intensity distribution at the return place decreases and the difficulties of identification of optical targets grow. The operating range can be as large as hundred kilometres under a weak-turbulence condition, decreasing rapidly to a kilometre level at strong turbulence.
\end{abstract}

Keywords: partially coherent Gaussian array beams, optical targets, cat-eye targets, atmosphere turbulence, coherence length.

PACS: $42.68 . J g$

UDC: 535.3

\section{Introduction}

Most of optical lenses used in photoelectric equipment have detectors fixed at their focal plane, such that the laser beam irradiating the equipment can be reflected back by the lens along the entrance way. This condition is called as a 'cat-eye effect' of optical target [1-4]. By using an active laser-detection technique based on this effect, optical targets can be efficiently distinguished from a background. Then longer detection distances and higher orientation precisions can be achieved, if compared with passive detection techniques [5-7]. However, in a modern city reconnaissance task, optical targets we wish to find are not too far away. For instance, the intensities of diffusively reflected light coming from walls and glasses are so large that we cannot confirm whether the signals acquired come from background or optical target. What is more, such 'harmless' optical targets as reporters' cameras could be mistakenly treated as an object.

To find 'dangerous' optical targets hidden against a strong-reflection background and distinguish a target's type, a new identification method based on active interference laser-beam scanning of optical targets has been proposed in Refs. [8, 9]. Using this method, space distribution of the reflected light can be transformed into measurable time series, whose periodic 
characteristics can be used to identify some optical characters, e.g. an optical aperture of the target. The main assumption made in Ref. [8] rests on the conditions of no turbulence available and a great coherence of laser beam. Only preliminary laboratory experiments have been performed in this direction [9]. Of course, the beam quality is reduced under any practical detection conditions, since the most of laser beams are only partially coherent, and the propagation properties can be changed by turbulence. Consequently, we suggest an analytical formulation of propagation of a coherently combined array of Gaussian beams issuing from a generalized Huygens-Fresnel principle. Moreover, below we report some simulations associated with the influences of laser coherence length and turbulence strength.

\section{Analytical formulae for partially coherent Gaussian array beams passing through an optical target}

Following Ref. [8], the time distribution of the reflected beam is not periodic whenever diffuse objects are scanned by a combined beam, which is equivalent to a single-beam scanning condition. So the main emphasis of our research is a combined-beam scanning of optical objects.

Partially coherent light is often used because of less influence, if compared with completely coherent light. It is known that Gaussian-Schell model (GSM) for the beams is widely employed to study the propagation of partially coherent light [10-12]. Below we will restrict our analysis to a simple one-dimensional linear array. In the Cartesian coordinate system, the transverse spectral density function for the beam combined with $2 N+1$ GSM beams in the plane $z=0$ is given by [10]

$$
\begin{aligned}
& W_{0}\left(y_{0}, y_{0}{ }^{\prime}\right)=\left\langle\left[\sum_{m} E\left(y_{0}-m d_{y}\right)\right]\left[\sum_{n} E\left(y_{0}{ }^{\prime}-n d_{y}\right)\right]^{*}\right\rangle \\
& =\sum_{m=-N}^{N} \sum_{n=-N}^{N} \exp \left[-\frac{\left(y_{0}-m d_{y}\right)^{2}+\left(y_{0}{ }^{\prime}-n d_{y}\right)^{2}}{\omega_{0}{ }^{2}}\right] \exp \left[-\frac{\left(y_{0}-y_{0}{ }^{\prime}-m d_{y}+n d_{y}\right)^{2}}{2 \sigma_{0}{ }^{2}}\right],
\end{aligned}
$$

where the symbols $<>$ and " denote respectively the ensemble average and the complex conjugate, $\omega_{0}$ and $\sigma_{0}$ are respectively the waist width and the correlation length of the GSM beam, $d_{y}$ is the spacing of adjacent beams along the $y$ direction, $m$ and $n$ are the beam-sequence numbers, and $E\left(y_{0}-m d y\right)$ and $E\left(y_{0}{ }^{\prime}-n d y\right)$ are the electric fields of the $m$-th and $n$-th GSM beams in the plane $z=0$, respectively.

Using the extended Huygens-Fresnel principle, one can represent the cross-spectral density function for the GSM beam, which propagates some distance $L$ in a turbulent atmosphere and arrives at the target place, as follows:

$$
\begin{aligned}
W_{1}\left(y_{1}, y_{1}^{\prime}\right)= & \frac{k}{2 \pi L} \int_{-\infty}^{\infty} \int_{-\infty}^{\infty} W_{0}\left(y_{0}, y_{0}^{\prime}\right) \exp \left\{\frac{\mathrm{i} k}{2 L}\left[\left(y_{1}^{2}-y_{1}^{\prime}\right)+\left(y_{0}^{2}-y_{0}^{\prime 2}\right)-2\left(y_{0} y_{1}-y_{0}^{\prime} y_{1}^{\prime}\right)\right]\right\} \\
& \times\left\langle\exp \left[\psi\left(y_{0}, y_{1}\right)+\psi^{*}\left(y_{0}^{\prime}, y_{1}^{\prime}\right)\right]\right\rangle \mathrm{d} y_{0} \mathrm{~d} y_{0}^{\prime}
\end{aligned}
$$

where $k$ is the wave number related to the wavelength $\lambda(k=2 \pi / \lambda)$ and $\psi\left(y_{0}, y_{1}\right)$ represents a random part of complex phase of a spherical wave due to the turbulence. The random phase can be written as

$$
\left\langle\exp \left[\psi\left(y_{0}, y_{1}\right)+\psi^{*}\left(y_{0}^{\prime}, y_{1}^{\prime}\right)\right]\right\rangle=\exp \left[-\frac{\left(y_{0}-y_{0}^{\prime}\right)^{2}}{\rho_{0}{ }^{2}}\right],
$$


where $\rho_{0}$ implies the coherence length of the spherical wave,

$$
\rho_{0}=\left(0.545 C_{n}^{2} k^{2} z\right)^{-3 / 5},
$$

with $C_{n}^{2}$ being the structure constant.

Through integration, Eq. (2) can be transformed into

$$
\begin{aligned}
W_{1}\left(y_{1}, y_{1}{ }^{\prime}\right) & =\frac{k}{2 L P_{1} P_{1}^{\prime}} \exp \left[\frac{\mathrm{i} k}{2 L}\left(y_{1}^{2}-y_{1}^{\prime 2}\right)\right] \sum_{m=-N}^{N} \sum_{n=-N}^{N} \exp \left[-\frac{\left(m d_{y}\right)^{2}+\left(n d_{y}\right)^{2}}{\omega_{0}^{2}}-\frac{\left(m d_{y}-n d_{y}\right)^{2}}{2 \sigma_{0}^{2}}\right] \\
& \times \exp \left\{-\frac{k^{2}}{4 P_{1}^{2} L^{2}}\left(y_{1}-Q_{1}\right)^{2}-\frac{k^{2}}{4 P_{1}^{\prime 2} L^{2}}\left[1+\frac{1}{P_{1}^{2} P_{1}^{\prime 2}}\left(\frac{1}{\rho_{0}^{2}}+\frac{1}{2 \sigma_{0}^{2}}\right)^{2}\right]\left(y_{1}^{\prime}-Q_{1}^{\prime}\right)^{2}\right\} \\
& \times \exp \left[\frac{k^{2}}{2 P_{1}^{2} P_{1}^{\prime 2} L^{2}}\left(\frac{1}{\rho_{0}^{2}}+\frac{1}{2 \sigma_{0}^{2}}\right)\left(y_{1}-Q_{1}\right)\left(y_{1}^{\prime}-Q_{1}^{\prime}\right)\right]
\end{aligned}
$$

where

$$
\begin{aligned}
& P_{1}^{\prime 2}=\frac{\mathrm{i} k}{2 L}+\frac{1}{\omega_{0}^{2}}+\frac{1}{2 \sigma_{0}^{2}}+\frac{1}{\rho_{0}^{2}}, \\
& P_{1}^{2}=-\frac{\mathrm{i} k}{2 L}+\frac{1}{\omega_{0}^{2}}+\frac{1}{2 \sigma_{0}^{2}}+\frac{1}{\rho_{0}^{2}}-\frac{1}{4 P_{1}^{\prime 2}}\left(\frac{2}{\rho_{0}^{2}}+\frac{1}{\sigma_{0}^{2}}\right)^{2}, \\
& Q_{1}^{\prime}=\frac{2 \mathrm{i} L n d_{y}}{k \omega_{0}^{2}}-\frac{\mathrm{i} L(m-n) d_{y}}{k \sigma_{0}^{2}}, \\
& Q_{1}=-\frac{2 \mathrm{i} L m d_{y}}{k \omega_{0}^{2}}-\frac{\mathrm{i} L(m-n) d_{y}}{k \sigma_{0}^{2}} .
\end{aligned}
$$

Basing on the propagation model represented by Fig. 2 in Ref. [8] and by the Collins formula, the cross-spectral density function of the GSM beam reflected by optical target reads as

$$
\begin{aligned}
W_{2}\left(y_{2}, y_{2}^{\prime}\right)= & \frac{k}{4 \pi f} \exp \left[\frac{\mathrm{i} k}{4 f}\left(y_{2}^{2}-y_{1}^{\prime 2}\right)\right] \int_{-\infty}^{\infty} \int_{-\infty}^{\infty} W_{1}\left(y_{1}, y_{1}^{\prime}\right) A_{1}\left(y_{1}\right) A_{1}^{*}\left(y_{1}^{\prime}\right) \\
& \times \exp \left\{\frac{\mathrm{i} k}{4 f}\left[\left(y_{1}^{2}-y_{1}^{\prime 2}\right)+2\left(y_{2} y_{1}-y_{2}^{\prime} y_{1}^{\prime}\right)\right]\right\} \mathrm{d} y_{1} \mathrm{~d} y_{1}^{\prime},
\end{aligned}
$$

where $f$ denotes the equivalent focus of the target optical lens and $A_{1}(y)$ the window function of entrance pupil of the target optical lens. The latter can be written as

$$
A_{1}(y)=\sum_{j=1}^{J} F_{j} \exp \left[-\frac{G_{j}\left(y-O_{y}\right)^{2}}{R^{2} \cos ^{2} \theta}\right],
$$

where $R$ and $\theta$ are respectively the aperture radius and the tilt angle of the optical target, $O_{y}$ denotes the position coordinate of the target optical lens along the $y$ direction when the scanning time is $t, F_{j}$ and $G_{j}$ are the expand modulus and compound Gaussian modulus which can be obtained by computer optimization, and $j$ is an integer value from 1 to $J$ (here $J=10$ ). For more details we refer the reader to Ref. [13]. 
After integrating Eq. (10), one obtains

$$
\begin{aligned}
& W_{2}\left(y_{2}, y_{2}^{\prime}\right)=\frac{k}{2 L P_{1} P_{1}^{\prime}} \frac{k}{4 f} \exp \left[\frac{\mathrm{i} k}{4 f}\left(y_{2}^{2}-y_{2}^{\prime 2}\right)\right] \\
& \times \sum_{m=-N}^{N} \sum_{n=-N}^{N} \sum_{j_{1}=1}^{J} \sum_{j_{2}=1}^{J} \frac{F_{j_{1}} F_{j_{2}}{ }^{*}}{P_{2}{ }^{\prime} P_{2}} \exp \left[-\frac{\left(m d_{y}\right)^{2}+\left(n d_{y}\right)^{2}}{\omega_{0}{ }^{2}}-\frac{\left(m d_{y}-n d_{y}\right)^{2}}{2 \sigma_{0}{ }^{2}}-\frac{\left(G_{j_{1}}+G_{j_{2}}{ }^{*}\right) O_{y}{ }^{2}}{R^{2} \cos ^{2} \theta}\right] \\
& \times \exp \left\{-\frac{k^{2} Q_{1}^{2}}{4 P_{1}^{2} L^{2}}-\frac{k^{2} Q_{1}^{\prime 2}}{4 P_{1}^{\prime 2} L^{2}}\left[1+\frac{1}{P_{1}^{2} P_{1}^{\prime 2}}\left(\frac{1}{\rho_{0}^{2}}+\frac{1}{2 \sigma_{0}^{2}}\right)^{2}\right]+\frac{k^{2} Q_{1} Q_{1}^{\prime}}{2 P_{1}^{2} P_{1}^{\prime 2} L^{2}}\left(\frac{1}{\rho_{0}^{2}}+\frac{1}{2 \sigma_{0}^{2}}\right)\right\} \\
& \times \exp \left\{-\frac{k^{2}}{16 f^{2} P_{2}^{2}}\left(y_{2}-Q_{2}\right)^{2}-\frac{k^{2}}{16 f^{2}{P_{2}^{\prime}}^{2}}\left[1-\frac{k^{4}}{16 P_{1}^{4}{P_{2}^{\prime}}^{4} P_{2}^{2}{P_{2}^{\prime}}^{2} L^{4}}\left(\frac{1}{\rho_{0}{ }^{2}}+\frac{1}{2 \sigma_{0}{ }^{2}}\right)^{2}\right]\left(y_{2}^{\prime}-Q_{2}^{\prime}\right)^{2}\right\} \\
& \times \exp \left[-\frac{k^{4}}{32 P_{1}^{2} P_{1}^{\prime 2} P_{2}^{2} P_{2}^{\prime 2} L^{2} f^{2}}\left(\frac{1}{\rho_{0}^{2}}+\frac{1}{2 \sigma_{0}^{2}}\right)\left(y_{2}-Q_{2}\right)\left(y_{2}^{\prime}-Q_{2}^{\prime}\right)\right],
\end{aligned}
$$

where

$$
\begin{aligned}
& P_{2}^{\prime 2}=\frac{\mathrm{i} k}{4 f}+\frac{\mathrm{i} k}{2 L}+\frac{k^{2}}{4 P_{1}^{\prime 2} L^{2}}\left[1+\frac{1}{P_{1}^{2}{P_{1}^{\prime 2}}^{2}}\left(\frac{1}{\rho_{0}{ }^{2}}+\frac{1}{2 \sigma_{0}^{2}}\right)^{2}\right]+\frac{G_{j_{2}}{ }^{*}}{R^{2} \cos ^{2} \theta},
\end{aligned}
$$

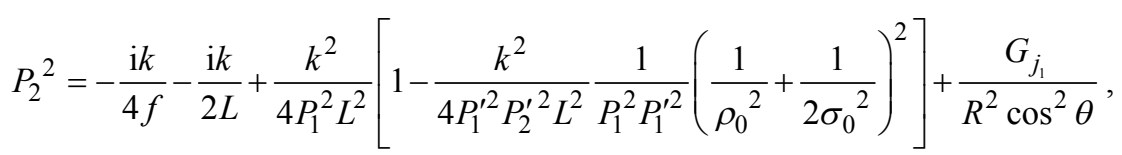

$$
\begin{aligned}
& Q_{2}{ }^{\prime}=-\frac{\mathrm{i} k f Q_{1}^{\prime}}{P_{1}^{\prime 2} L^{2}}\left[1+\frac{1}{P_{1}^{2} P_{1}^{\prime 2}}\left(\frac{1}{\rho_{0}^{2}}+\frac{1}{2 \sigma_{0}^{2}}\right)^{2}\right]+\frac{\mathrm{i} k f Q_{1}}{P_{1}^{2} P_{1}^{\prime 2} L^{2}}\left(\frac{1}{\rho_{0}{ }^{2}}+\frac{1}{2 \sigma_{0}^{2}}\right)-\frac{4 \mathrm{i} f O_{y} G_{j_{2}}{ }^{*}}{k R^{2} \cos ^{2} \theta} \text {, } \\
& Q_{2}=\frac{\mathrm{i} k f Q_{1}}{P_{1}^{2} L^{2}}-\frac{\mathrm{i} k f Q_{1}^{\prime}}{P_{1}^{2} P_{1}^{\prime 2} L^{2}}\left(\frac{1}{\rho_{0}^{2}}+\frac{1}{2 \sigma_{0}^{2}}\right)+\frac{4 \mathrm{i} f O_{y} G_{j_{1}}}{k R^{2} \cos ^{2} \theta} .
\end{aligned}
$$

Using the extended Huygens-Fresnel principle once again, one can obtain the cross-spectral density function for the GSM beam propagating the distance $L$ in the turbulent atmosphere and arriving at the return place as follows:

$$
\begin{aligned}
W_{3}\left(y_{3}, y_{3}^{\prime}\right)= & \frac{k}{2 \pi L} \int_{-\infty}^{\infty} \int_{-\infty}^{\infty} W_{2}\left(y_{2}, y_{2}^{\prime}\right) A_{2}\left(y_{2}\right) A_{2}^{*}\left(y_{2}^{\prime}\right) \\
& \times \exp \left\{\frac{\mathrm{i} k}{2 L}\left[\left(y_{3}^{2}-y_{3}^{\prime 2}\right)+\left(y_{2}^{2}-y_{2}^{\prime 2}\right)-2\left(y_{2} y_{3}-y_{2}^{\prime} y_{3}^{\prime}\right)\right]\right\} \\
& \times\left\langle\exp \left[\psi\left(y_{2}, y_{3}\right)+\psi^{*}\left(y_{2}^{\prime}, y_{3}^{\prime}\right)\right]\right\rangle \mathrm{d} y_{2} \mathrm{~d} y_{2}^{\prime},
\end{aligned}
$$

where

$$
A_{2}(y)=\sum_{j=1}^{J} F_{j} \exp \left[-\frac{G_{j}\left(y-O_{y}-2 f \tan \theta\right)^{2}}{R^{2} \cos ^{2} \theta}\right]
$$

is the window function of entrance pupil of the target optical lens. So we can get 


$$
\begin{aligned}
& W_{3}\left(y_{3}, y_{3}^{\prime}\right)=\frac{k}{2 L P_{1} P_{1}^{\prime}} \frac{k}{4 f} \frac{k}{2 L} \exp \left[\frac{\mathrm{i} k}{2 L}\left(y_{3}^{2}-y_{3}^{\prime 2}\right)\right] \\
& \times \sum_{m=-N}^{N} \sum_{n=-N}^{N} \sum_{j_{1}=1}^{J} \sum_{j_{2}=1}^{J} \sum_{j_{3}=1}^{J} \sum_{j_{4}=1}^{J} \frac{F_{j_{1}} F_{j_{2}}{ }^{*} F_{j_{3}} F_{j_{4}}{ }^{*}}{P_{2} P_{2}^{\prime} P_{3} P_{3}^{\prime}} \exp \left[-\frac{\left(m d_{y}\right)^{2}+\left(n d_{y}\right)^{2}}{\omega_{0}{ }^{2}}-\frac{\left(m d_{y}-n d_{y}\right)^{2}}{2 \sigma_{0}{ }^{2}}\right] \\
& \times \exp \left[-\frac{\left(G_{j_{1}}+G_{j_{2}}^{*}\right) O_{y}^{2}}{R^{2} \cos ^{2} \theta}-\frac{\left(G_{j_{3}}+G_{j_{4}}^{*}\right)\left(O_{y}+2 f \tan \theta\right)^{2}}{R^{2} \cos ^{2} \theta}\right] \\
& \times \exp \left\{-\frac{k^{2} Q_{1}^{2}}{4 L^{2} P_{1}^{2}}-\frac{k^{2} Q_{1}^{\prime 2}}{4 L^{2} P_{1}^{\prime 2}}\left[1+\frac{1}{P_{1}^{2} P_{1}^{\prime 2}}\left(\frac{1}{\rho_{0}^{2}}+\frac{1}{2 \sigma_{0}^{2}}\right)^{2}\right]+\frac{k^{2} Q_{1} Q_{1}^{\prime}}{2 P_{1}^{2} P_{1}^{\prime 2} L^{2}}\left(\frac{1}{\rho_{0}^{2}}+\frac{1}{2 \sigma_{0}^{2}}\right)\right\} \\
& \times \exp \left\{\frac{\mathrm{i} k Q_{2}^{2}}{8 f P_{2}^{2}}-\frac{\mathrm{i} k Q_{2}^{\prime 2}}{8 f P_{2}^{\prime 2}}\left[1-\frac{k^{4}}{16 P_{1}^{4} P_{1}^{\prime 4} P_{2}^{2} P_{2}^{\prime 2} L^{4}}\left(\frac{1}{\rho_{0}^{2}}+\frac{1}{2 \sigma_{0}^{2}}\right)^{2}\right]\right\} \\
& \times \exp \left[\frac{\mathrm{i} k^{3} Q_{2} Q_{2}{ }^{\prime}}{16 P_{1}^{2} P_{1}^{\prime 2} P_{2}^{2} P_{2}^{\prime 2} L^{2} f}\left(\frac{1}{\rho_{0}^{2}}+\frac{1}{2 \sigma_{0}^{2}}\right)\right] \exp \left[-\frac{k^{2}}{4 L^{2} P_{3}^{2}}\left(y_{3}-Q_{3}\right)^{2}\right] \\
& \times \exp \left[-\frac{k^{2}}{4 L^{2} P_{3}^{\prime 2}}\left\{1-\frac{1}{4 P_{3}^{2} P_{3}^{\prime 2}}\left[\frac{\mathrm{i} k^{3}}{16 P_{1}^{2} P_{1}^{\prime 2} P_{2}^{2} P_{2}^{\prime 2} L^{2} f}\left(\frac{1}{\rho_{0}^{2}}+\frac{1}{2 \sigma_{0}^{2}}\right)+\frac{2}{\rho_{0}^{2}}\right]^{2}\right\}\left(y_{3}^{\prime}-Q_{3}^{\prime}\right)^{2}\right] \\
& \times \exp \left\{-\frac{k^{2}}{8 L^{2} P_{3}^{2} P_{3}^{\prime 2}}\left[\frac{i k^{3}}{16 P_{1}^{2} P_{1}^{\prime 2} P_{2}^{2} P_{2}^{\prime 2} L^{2} f}\left(\frac{1}{\rho_{0}^{2}}+\frac{1}{2 \sigma_{0}^{2}}\right)+\frac{2}{\rho_{0}^{2}}\right]\left(y_{3}-Q_{3}\right)\left(y_{3}^{\prime}-Q_{3}^{\prime}\right)\right\},
\end{aligned}
$$

where

$$
\begin{aligned}
& P_{3}^{\prime 2}=\frac{\mathrm{i} k}{4 f}+\frac{\mathrm{i} k}{2 L}+\frac{1}{\rho_{0}^{2}}+\frac{\mathrm{i} k}{8 f P_{2}^{\prime 2}}\left[1-\frac{k^{4}}{16 P_{1}^{4} P_{1}^{\prime 4} P_{2}^{2} P_{2}^{\prime 2} L^{4}}\left(\frac{1}{\rho_{0}^{2}}+\frac{1}{2 \sigma_{0}^{2}}\right)^{2}\right]+\frac{G_{j_{4}}^{*}}{R^{2} \cos ^{2} \theta},(20) \\
& P_{3}^{2}=-\frac{\mathrm{i} k}{4 f}-\frac{\mathrm{i} k}{2 L}+\frac{3}{\rho_{0}^{2}}+\frac{G_{j_{3}}}{R^{2} \cos ^{2} \theta} \\
& -\frac{\mathrm{i} k}{8 f P_{2}^{2}}\left[1+\frac{\mathrm{i} k}{8 f P_{2}^{\prime 2} P_{3}^{\prime 2}} \frac{k^{4}}{16 P_{1}^{4} P_{1}^{\prime 4} P_{2}^{2} P_{2}^{\prime 2} L^{4}}\left(\frac{1}{\rho_{0}^{2}}+\frac{1}{2 \sigma_{0}^{2}}\right)^{2}\right] \text {, } \\
& Q_{3}{ }^{\prime}=-\frac{L Q_{2}^{\prime}}{4 f P_{2}^{\prime 2}}\left[1-\frac{k^{4}}{16 P_{1}^{4} P_{1}^{\prime 4} P_{2}^{2} P_{2}^{\prime 2} L^{4}}\left(\frac{1}{\rho_{0}^{2}}+\frac{1}{2 \sigma_{0}^{2}}\right)^{2}\right] \\
& +\frac{k^{2} Q_{2}}{16 P_{1}^{2} P_{1}^{\prime 2} P_{2}^{2} P_{2}^{\prime 2} L f}\left(\frac{1}{\rho_{0}^{2}}+\frac{1}{2 \sigma_{0}^{2}}\right)+\frac{2 \mathrm{i} L G_{j_{4}}^{*}\left(O_{y}+2 f \tan \theta\right)}{k R^{2} \cos ^{2} \theta} \\
& Q_{3}=-\frac{L Q_{2}}{4 f P_{2}^{2}}-\frac{k^{2} Q_{2}^{\prime}}{16 P_{1}^{2} P_{1}^{\prime 2} P_{2}^{2} P_{2}^{\prime 2} L f}\left(\frac{1}{\rho_{0}^{2}}+\frac{1}{2 \sigma_{0}^{2}}\right)-\frac{2 \mathrm{i} L G_{j_{3}}\left(O_{y}+2 f \tan \theta\right)}{k R^{2} \cos ^{2} \theta} .
\end{aligned}
$$

When $y_{3}=y_{3}{ }^{\prime}$, the light intensity distribution at the return place is 


$$
I_{3}\left(y_{3}\right)=W_{3}\left(y_{3}, y_{3}\right) .
$$

When the synthetic beam scans the target, $I_{3}(0)$ changes with changing position coordinate $O_{y}$ and scanning time $t$.

The spatial coherence between two points is defined as

$$
u\left(y, y^{\prime}\right)=\frac{W\left(y, y^{\prime}\right)}{\left[I(y) I\left(y^{\prime}\right)\right]^{1 / 2}} .
$$

The beam spatial degrees of coherence at the target and return places can be obtained from this formula. Moreover, the light intensity distribution at the target place and the coherence, which are the major factors that influence the reflection characteristics, can also be obtained. When $y_{1}=y_{1}{ }^{\prime}$, the light intensity distribution at the target place is given by

$$
\begin{aligned}
I_{1}\left(y_{1}\right)= & W_{1}\left(y_{1}, y_{1}\right) \\
= & \frac{k}{2 L P_{1}^{\prime} P_{1}} \sum_{m=-N}^{N} \sum_{n=-N}^{N} \exp \left[-\frac{\left(m d_{y}\right)^{2}+\left(n d_{y}\right)^{2}}{\omega_{0}^{2}}-\frac{\left(m d_{y}-n d_{y}\right)^{2}}{2 \sigma_{0}^{2}}\right] \\
& \times \exp \left\{-\frac{k^{2}}{4 P_{1}^{2} L^{2}}\left(y_{1}-Q_{1}\right)^{2}-\frac{k^{2}}{4 P_{1}^{\prime 2} L^{2}}\left[1+\frac{1}{P_{1}^{2} P_{1}^{\prime 2}}\left(\frac{1}{\rho_{0}^{2}}+\frac{1}{2 \sigma_{0}^{2}}\right)^{2}\right]\left(y_{1}-Q_{1}^{\prime}\right)^{2}\right\} \\
& \times \exp \left[\frac{k^{2}}{2 P_{1}^{2} P_{1}^{\prime 2} L^{2}}\left(\frac{1}{\rho_{0}^{2}}+\frac{1}{2 \sigma_{0}^{2}}\right)\left(y_{1}-Q_{1}\right)\left(y_{1}-Q_{1}^{\prime}\right)\right] .
\end{aligned}
$$

In the special case of $n=0$ (i.e., for a single beam), the spatial coherence at the target place for the two axially symmetric points $y_{1}$ and $-y_{1}$ in the plane $z=L$ reads as

$$
u_{10}\left(y_{1},-y_{1}\right)=\frac{W_{1}\left(y_{1},-y_{1}\right)}{\left[I_{1}\left(y_{1}\right) I_{1}\left(-y_{1}\right)\right]^{1 / 2}}=\exp \left[-\frac{k^{2}}{P_{1}^{2} P_{1}^{\prime 2} L^{2}}\left(\frac{1}{\rho_{0}^{2}}+\frac{1}{2 \sigma_{0}^{2}}\right) y_{1}^{2}\right] \text {. }
$$

From Eq. (27), one can deduce that the spatial coherence between two points of a single beam is determined by the spatial correlation length of the initial surface, the refractive index, the structure constant, the waist radius, the detection distance and some other parameters. Furthermore, the spatial coherence has a strongly influence on the synthetic intensity at the target place. Issuing from these points, we present in the next section some numerical calculations for the spatial coherence and the synthetic intensity.

\section{Numerical calculations}

In our calculation we assume $\omega_{0}=1 \mathrm{~mm}, \lambda=532 \mathrm{~nm}, L=500 \mathrm{~m}, f=0.5 \mathrm{~m}$ and $d_{y}=8 \mathrm{~mm}$. Besides, we assume that the scanning speed $v_{y}$ is equal to $0.1 \mathrm{rad} / \mathrm{s}$, the initial position coordinate is zero (then we have $O_{y}=-v_{y} t$ ), and the relative spatial correlation length of $\sigma$ is given by $\sigma_{0} / \omega_{0}$. To analyze the synthesis-light intensity distribution and the spatial coherence at the target place, we assume $N=2$. Fig. 1 displays the synthesis-light intensity distribution at the target place under different turbulences, when the $\sigma$ parameter is equal to unity. One can see that the fringe contrast of the synthesis-light intensity decrease rapidly with increasing turbulence. There are almost no distribution peaks till the turbulence is large enough, and the intensity-distribution pattern has almost a Gauss profile. Then the frequency information in the intensity distribution vanishes gradually. 

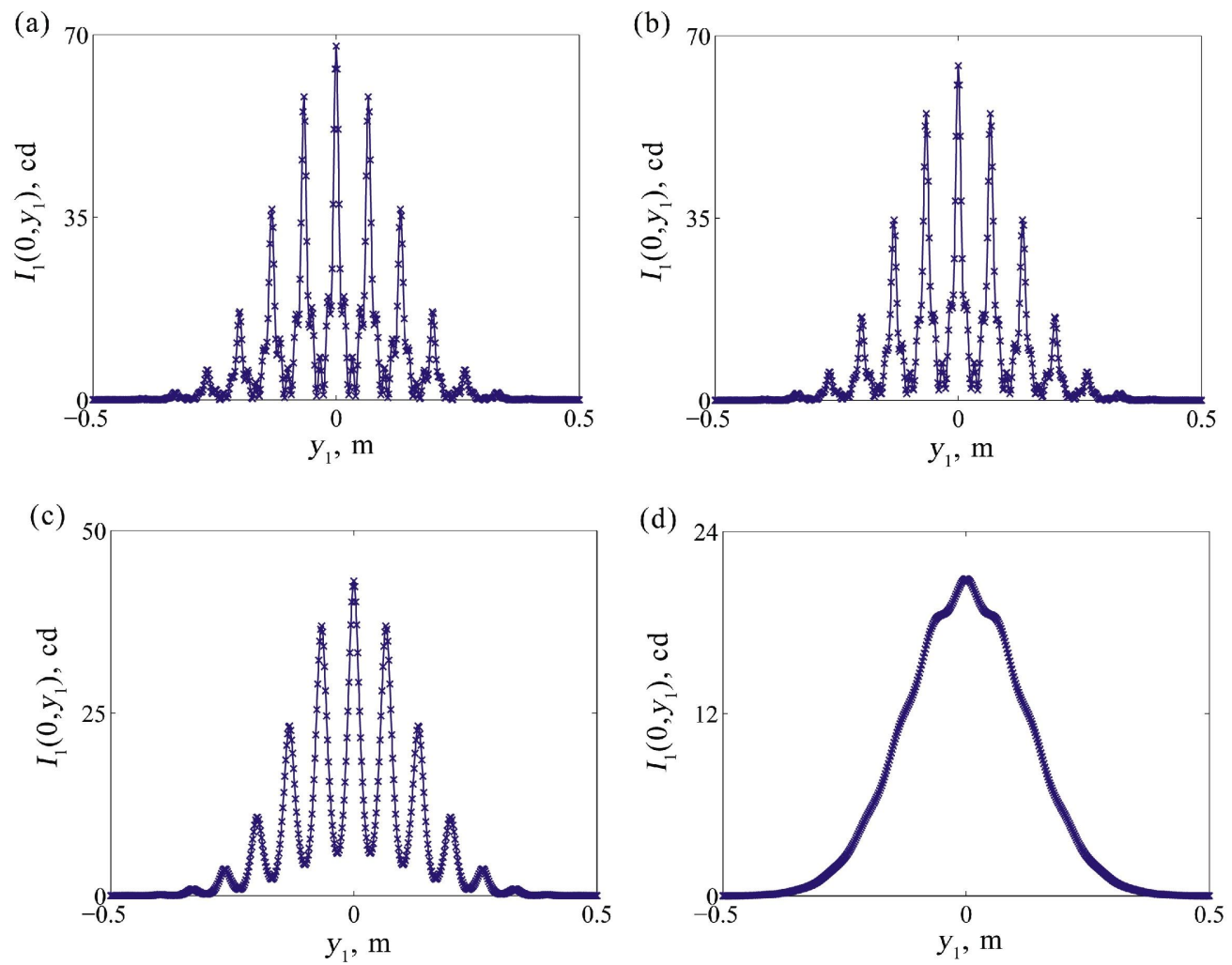

Fig. 1. Light intensity distributions calculated at the target place for different turbulences: $C_{n}^{2}=0$ (a), $10^{-14}$ (b), $10^{-13}$ (c) and $10^{-12} \mathrm{~m}^{-2 / 3}(\mathrm{~d})$.
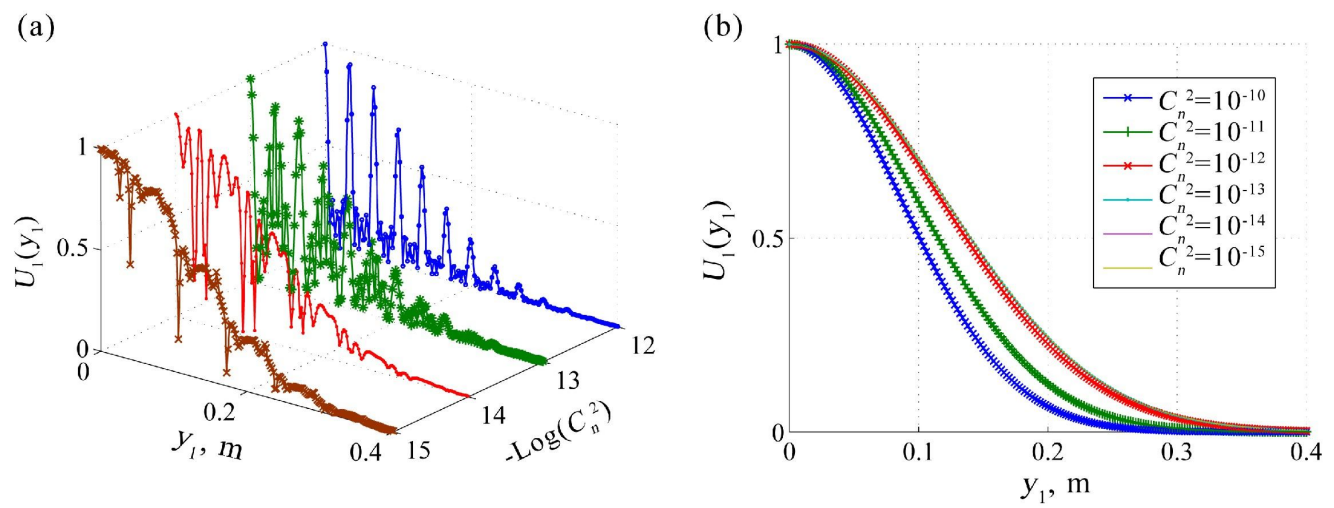

Fig. 2. Radial changes in spatial coherence degree calculated at the target place for different turbulences: $N=2$ (a) and $N=0$ (b).

In order to study variations in the spatial coherence caused by enhanced turbulence, we have performed some additional simulations. Fig. 2a shows radial variations of the spatial coherence at the target place. One can see that increasing turbulence gives rise to more minimum points. When the turbulence is strong enough, most of them become very weak. Moreover, the curve is oscillating rather than smooth. This can be explained such that the two axisymmetric points become irrelevant because of the equivocal phase relationships. Then we have performed some simulations with the case of single beam. It can be seen from Fig. $2 \mathrm{~b}$ that there are no oscillations, 
and the spatial coherence decreases with increasing radial length. The enhancement of turbulence makes this decrease faster. However, the turbulence makes no difference whenever the $C_{n}^{2}$ parameter gets smaller than $10^{-13}$.

(a)

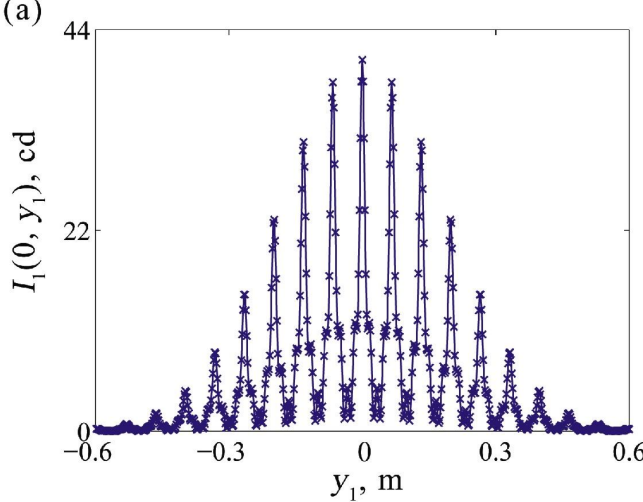

(c)

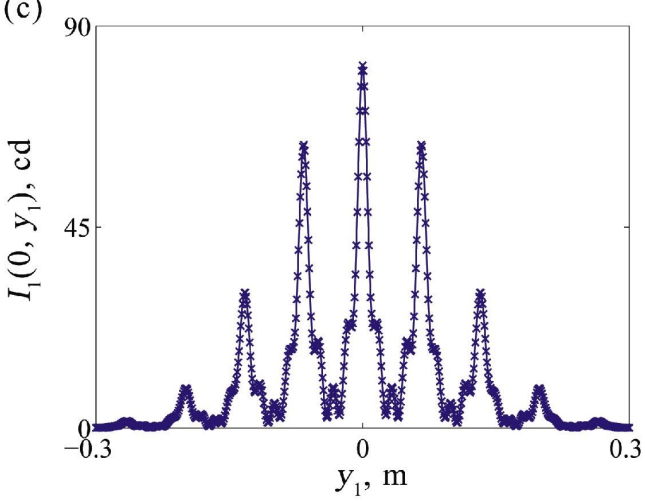

(b)

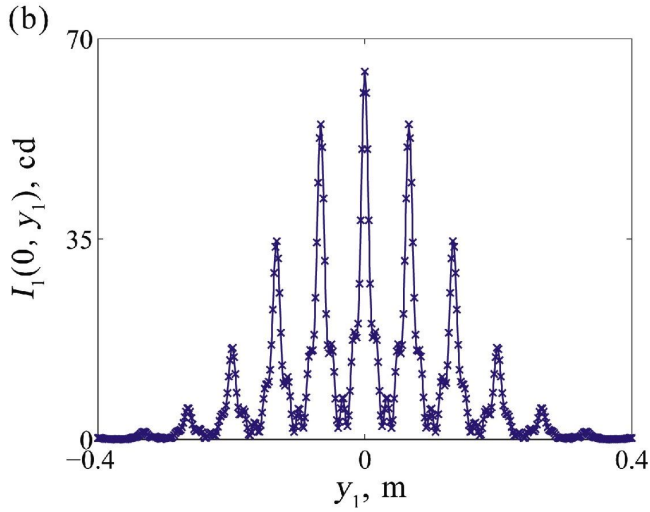

(d)

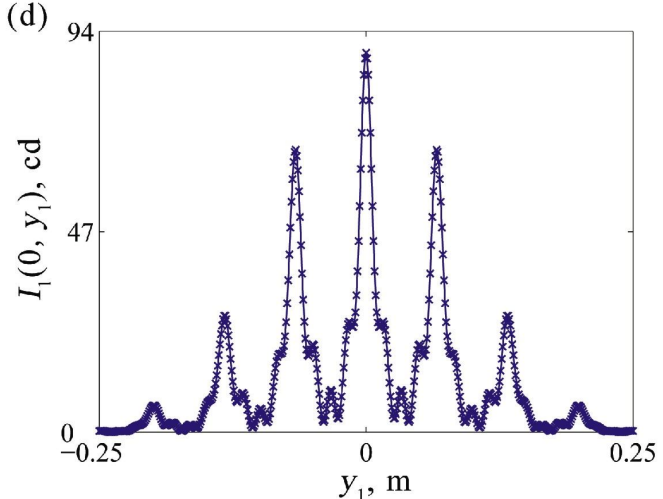

Fig. 3. Light intensity distributions calculated at the target place for different laser coherence lengths: $\sigma=0.5(a), 1(b), 2(c)$ and $5(d)$.
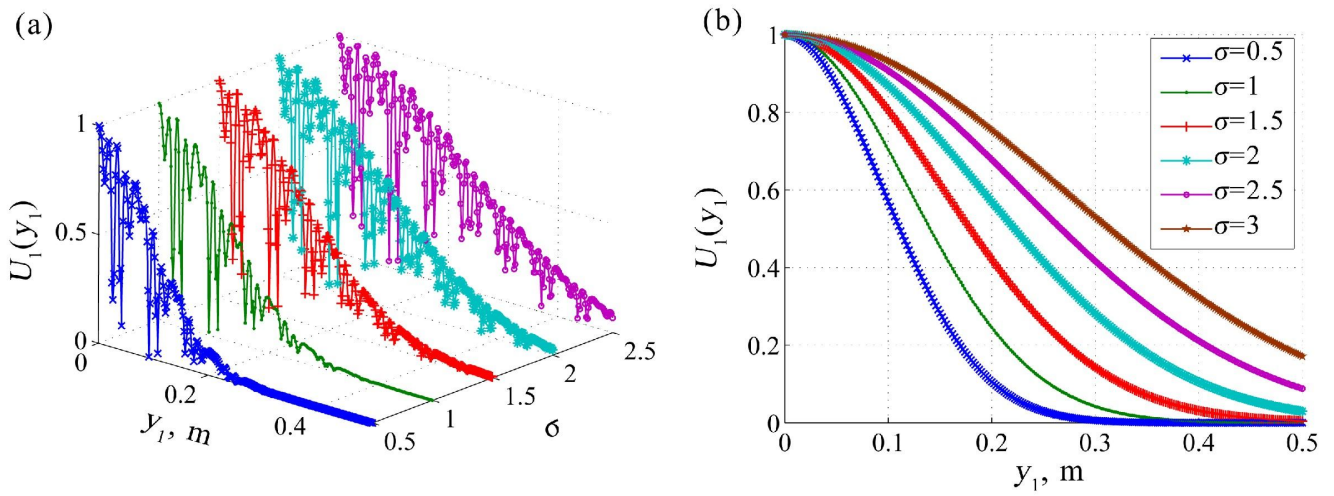

Fig. 4. Radial changes in spatial coherence degree calculated at the target place for different laser coherence lengths: $N=2$ (a) and $N=0$ (b).

Fig. 3 shows the light intensity distribution at the target place calculated for different laser coherence lengths. The smaller the correlation length, the broader is the beam in the turbulent atmosphere and the more peaks are available in the interference intensity curve. When the 
correlation length increases, the peak intensity and the peak contrast become larger. Fig. 4 shows radial changes in the spatial coherence degree at the target place at different laser coherence lengths. The differences among the cases of single and multiple beams are similar to those seen from Fig. 2. In particular, the spatial coherence increases rapidly with increasing coherence length.

(a)

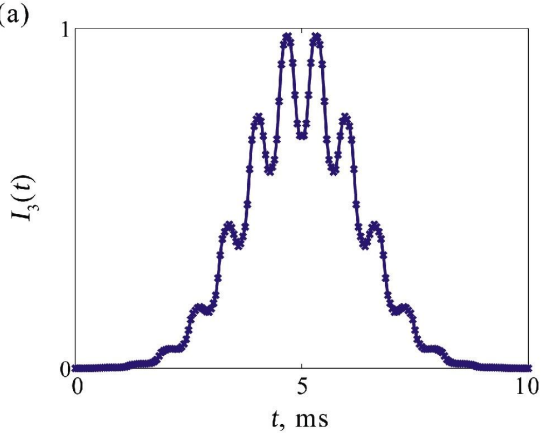

(b)

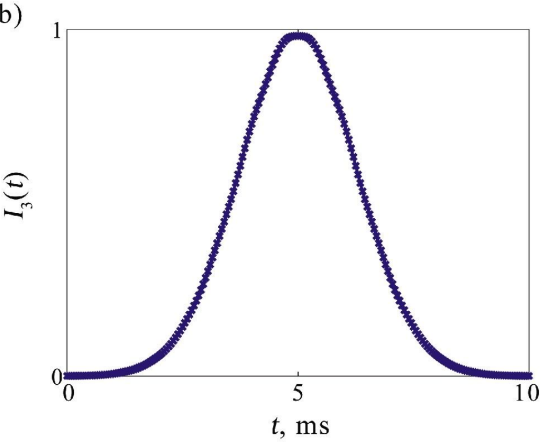

Fig. 5. Normalized light intensity distributions calculated at the return place for different turbulences: $C_{n}^{2}=10^{-14} \mathrm{~m}^{-2 / 3}(\mathrm{a})$ and $C_{n}^{2}=10^{-12} \mathrm{~m}^{-2 / 3}(\mathrm{~b})$.

Basing on the above results, one can conclude that the turbulence intensity is the key factor that determines formation of interference fringes. As a consequence, our further studies are related to the changes in light intensity observed at the return place under conditions of different

(a)

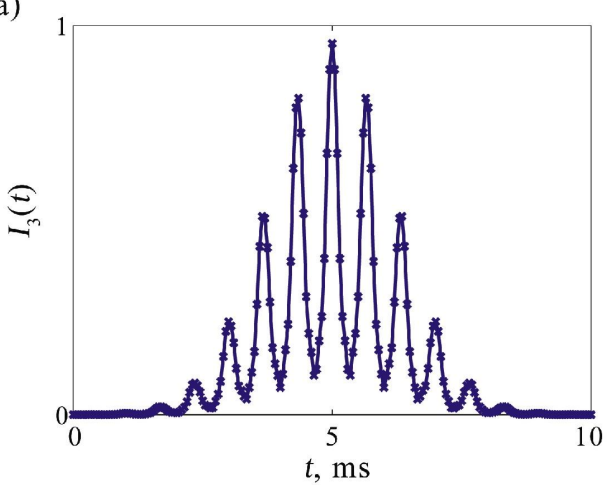

(c)

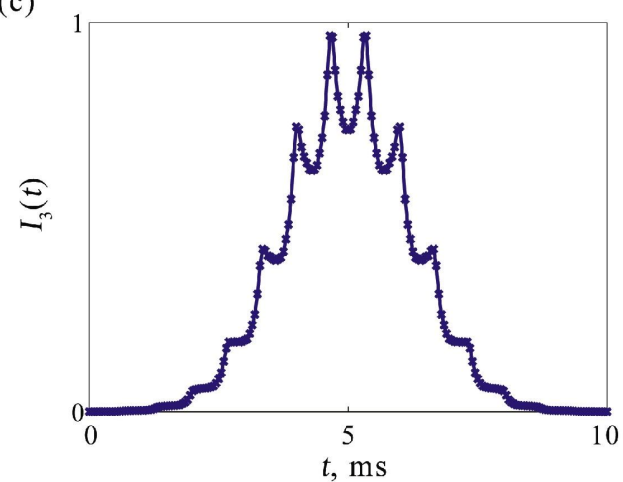

(b)

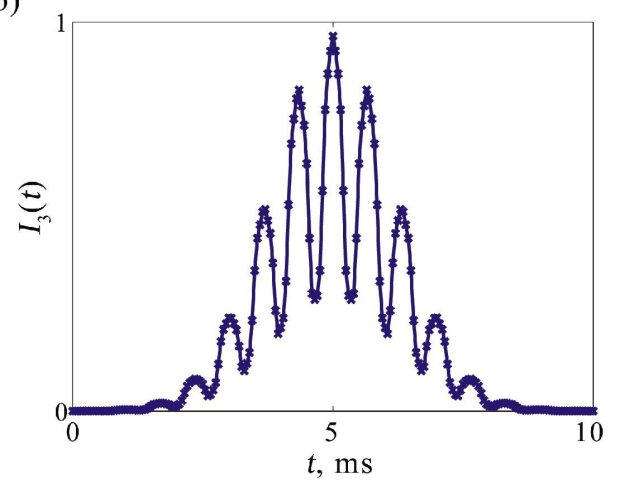

(d)

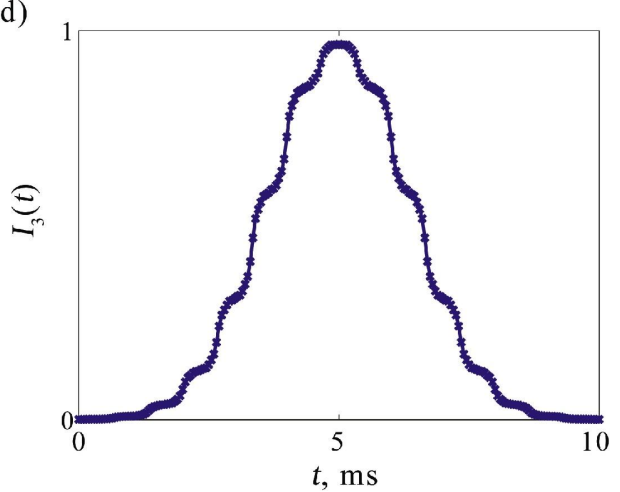

Fig. 6. Normalized light intensity distributions calculated at the return place for different target-aperture diameters: $D=10(\mathrm{a}), 20$ (b), 40 (c) and $100 \mathrm{~mm}(\mathrm{~d})$. 
turbulences and target apertures. Fig. 5 shows the normalized light intensity distributions at the return place at different turbulences. Here the intensity is measured in relative dimensionless units. When the turbulence is weak, the profile of the distribution is still Gaussian, although the contrast at the return place is much smaller than that at the target place (cf. with the data presented in Fig. 3). Note also that the spatial distributions in Fig. 3 would turn into time distributions when the scanning is being conducted. If we have the inequality $C_{n}^{2}<10^{-13} \mathrm{~m}^{-2 / 3}$, the distribution profile is stable with increasing $C_{n}{ }^{2}$. The contrast decreases rapidly under this condition. Finally, if the $C_{n}^{2}$ parameter increases to $10^{-12} \mathrm{~m}^{-2 / 3}$, both the periodicity and the peaks vanish.

Fig. 6 displays the normalized light intensity distributions at the return place under different target-aperture diameters at the conditions $\sigma=1, C_{n}{ }^{2}=10^{-14} \mathrm{~m}^{-2 / 3}$ and the diameter $D=2 R$. When the aperture diameter remains small, the distribution shape at the return place is similar to that at the target place. When the fringe width at the target place is invariable, a bigger aperture diameter leads to worse contrast at the return place. Moreover, then the peaks disappear more rapidly with increasing $D$ than in the case described by Fig. 4 in Ref. [8]. There are no peaks till the $D$ parameter reaches the value $D=100 \mathrm{~mm}$. In other words, the intensity distribution at the return place is periodical only when the target-aperture diameter remains less than the interval among the peaks at the target place.

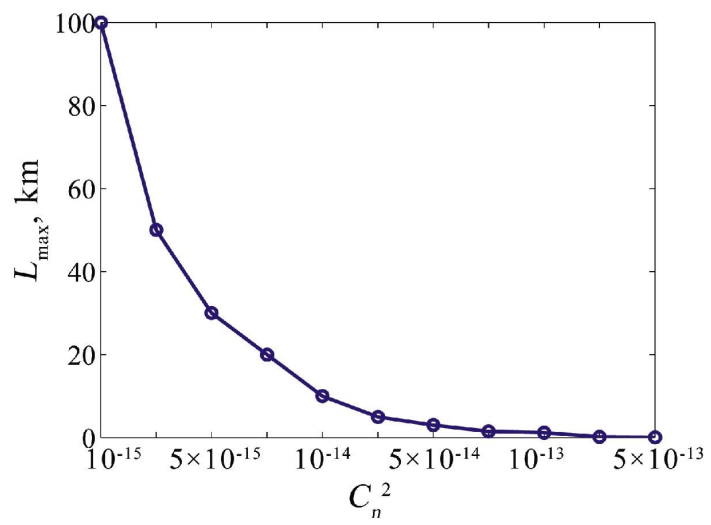

Fig. 7. Dependence of propagation distance ensuring enough interference contrast on the $C_{n}{ }^{2}$ parameter (see the text).

Since the propagation distance has an important influence on the light distribution contrast, we have undertaken the appropriate calculations. Below we define the contrast to be enough if the maximum intensity is twice the minimum intensity and assume the additional conditions $\sigma=1$ and $d_{y}=0.008 \mathrm{~mm}$. As seen from Fig. 7, a satisfactory interference fringe can be obtained with the distances of the order of $100 \mathrm{~km}$, whenever $C_{n}^{2}=10^{-15} \mathrm{~m}^{-2 / 3}$. On the other hand, when we have $C_{n}^{2}=10^{-13} \mathrm{~m}^{-2 / 3}$, this distance drops down to only $1.2 \mathrm{~km}$. Therefore the propagation distance decreases rapidly with increasing turbulence. Nonetheless, one can obtain a better interference effect after improving beam quality.

\section{Conclusion}

In the present work we have studied the influences of atmosphere turbulence and laser coherence on the interference scanning recognition technique that employs active-interference laser beams. Our studies represent a much more broader and deeper version of the work done by the authors of 
Ref. [8]. In contrast to the earlier literature data, we have obtained more practical results. We have suggested analytical formulation of the propagation of partially coherent Gaussian array beams that pass through an optical target and go back along the entrance way in the turbulent atmosphere. The problem is considered using the generalized Huygens-Fresnel principle. A number of simulations have been performed to study the influences of the laser coherence length and the turbulence strength. Our results testify that with strengthening turbulence and decreasing laser coherence length reduce gradually the fringe contrast and the degree of spatial coherence, thus increasing practical recognition difficulties. Under condition of weak turbulence, the propagation distance can be equal a hundred kilometres. However, when the turbulence is strong enough, the propagation distance is cut down to only $1.2 \mathrm{~km}$. Notice that if a single longitudinal-mode laser is used under the condition of moderate turbulence, the propagation distance can be improved to almost $3 \mathrm{~km}$.

\section{Acknowledgement}

This work is supported by the National Natural Science Foundation of China under the Grant Number 61302183.

\section{References}

1. Lecocq C, Deshors G, Lado-Bordowsky O and Meyzonnette J L, 2003. Sight laser detection modeling. Proc. SPIE. 5086: 280-286.

2. Mieremet A L, Ric H M A Schleijpen, van Putten F J M and Veerman H, 2010. Retroreflection reduction by masking apertures. Opt. Eng. 49: 043202.

3. Lei Peng, Sun Ke, Zhang Yufa, Li Feng, Nie Jingsong and Sun Xiaoquan, 2016. Cat's eye echo-wave characteristics of staring photoelectric imaging system. Acta Photon. Sin. 45: 0614004 .

4. Wu Dongsheng, Liu Bingqi, Hu Wengang and Ying Jiaju, 2016. Echo characteristics models of cat-eye effect based on matrix optics. Acta Opt. Sin. 36: 0608001.

5. Weijian Jian, Li Li and Xiaoyue Zhang, 2015. Cat-eye effect target recognition with singlepixel detectors. Opt. Commun. 357: 21-27.

6. Yang Mingyu, 2015. Detecting of photoelectric peeping devices based on active laser detection. Chin. Opt. 8: 255-262.

7. Zhao Yan-zhong, Sun Hua-yan, Zheng Yong-hui, Shan Cong-miao and Fan You-chen, 2014. Opt. Laser Technol. 58: 1-7.

8. Zhao Yanzhong, Sun Huayan, Zheng Yonghui and Zhang Xi, 2011. Theoretical analysis of scanning and identifying cat-eye target with coherently combined array Gaussian beams. Acta Opt. Sin. 31: 0412002.

9. Zhao Yanzhong, Sun Huayan, Shan Congmiao, Zheng Yonghui and Zhang Laixian, 2014. A new identification method aimed at optical targets using an active interference laser beam. IEEE Photon. Technol. Lett. 26: 1019-1022.

10. Mao Yonghua, Mei Zhangrong and Gu Juguan, 2016. Propagation of Gaussian shell-model array beams in free space and atmospheric turbulence. Opt. Laser Technol. 86: 14-20.

11. Zhou Zhaotao, Guo Mengwen and Zhao Daomu, 2017. Propagation of specular and antispecular Gaussian Schell-model beams in oceanic turbulence. Opt. Commun. 383: 287-293.

12. Nelson C, Avramov-Zamurovic S, Korotkova O, Guth S and Malek-Madani R, 2016. Scintillation reduction in pseudo multi-Gaussian Schell model beams in the maritime environment. Opt. Commun. 364: 145-149. 
13. Wen J J and Breazeale M A, 1988. A diffraction beam field expressed as the super-position of Gaussian beams. J. Acoust Soc. Amer. 83: 1752-1756.

Zhao Yan-zhong, He Ting, Shan Cong-miao and Sun Hua-yan. 2017. Influence of atmosphere turbulence and laser coherence on the identification method based on interference multiple-beam scanning of optical targets. Ukr.J.Phys.Opt. 18: $213-224$

Анотація. 3 використанням узагальненого дифракційного інтеграла Гюйтенса-Френеля одержано аналітичні формули для опису частково когерентного набору гаусових променів, щзо проходять крізь оптичну мімень $i$ йдуть назад тим же иляхом у турбулентній атмосфері. Вони включають розподіл інтенсивності світла в місці повернення, а також розподіл інтенсивності світла та просторову кореляцію в цільовому місиі. На підставі чисельних розрахунків вивчено вплив довжини когерентності лазера та сили турбулентності на контраст інтерферениійних смуг і ступінь просторової когерентності в цільовому місці, а також розподіл інтенсивності світла в місці повернення та робочий діапазон системи. Виявлено, щзо контраст смуг $і$ ступінь просторової когерентності в иільовому місиі зменшуються з посиленням сили турбулентності та зменшенням когерентної довжини лазера. Тоді контраст розподілу інтенсивності світла в місиі повернення понижується, а складність ідентифікації оптичних иілей зростає. В умовах слабкої турбулентності робочий діапазон може складати сотню кілометрів, швидко зменшуючись до рівня кілометрів за умови сильної турбулентності. 